\author{
$\$$ Research Square \\ Nasar Alwahaibi ( $\nabla$ nasar@squ.edu.om ) \\ Sultan Qaboos University \\ Muna Al Maskari \\ Sultan Qaboos University \\ Buthaina Al Dhahli \\ Sultan Qaboos University \\ Halima Al Issaei \\ Sultan Qaboos University \\ Samiya Al-Jaaidi \\ Sultan Qaboos University \\ Shadia Al Bahlani \\ Sultan Qaboos University
}

Preprints are preliminary reports that have not undergone peer review.

They should not be considered conclusive, used to inform clinical practice, or referenced by the media as validated information.

\title{
One-year review of COVID-19 in the Arab world
}

\section{Research Article}

Keywords: Arab world, Coronavirus, COVID-19, SARS-CoV-2

Posted Date: April 8th, 2021

DOl: https://doi.org/10.21203/rs.3.rs-400603/v1

License: (c) (i) This work is licensed under a Creative Commons Attribution 4.0 International License. Read Full License

Version of Record: A version of this preprint was published at Qatar Medical Journal on November 23rd, 2021. See the published version at https://doi.org/10.5339/qmj.2021.66. 


\title{
One-year review of COVID-19 in the Arab world
}

\begin{abstract}
Aim: Coronavirus disease 2019 (COVID-19) has infected almost every country worldwide, including all 22 Arab countries. We have been following the COVID-19 pandemic in all Arab countries since it started. In this review, we aimed to assess the prevalence of COVID-19 in the Arab world for twelve months and to compare these findings with other most affected countries. Methods: World Health Organization, Worldometer and Ministries of Health websites were used to search for COVID-19 data in all Arab countries. The period was from February 2020 to February 2021. The data was analyzed using the Statistical Package for the Social Sciences (SPSS) software version 23. Results: The median age in all Arab countries was 26.25. As of March 01, 2021, the total confirmed cases of COVID-19 in all Arab countries were 4,259,756. Iraq, Morocco, Jordan, United Arab Emirates and Saudi Arabia (SA) have the highest reported cases with, 695,489, 483,766, 391,090, 390,453 and 377,383, respectively. The total number of deaths were 72,950 cases and were dominant in Iraq, followed by Egypt, Morocco, Tunisia and SA with 13,406, 10736, 8637, 8022 and 6494, respectively. In comparison with the topmost affected countries, the data obtained from COVID-19 confirmed cases showed that Arab countries are ranked fourth after USA, India, and Brazil. In terms of total deaths per million, Arab countries come in the second last, before India, with only 165 cases. Conclusion: The number of confirmed and death cases among all Arab countries trigger vital worries about morbidity and mortality of COVID-19, respectively. However, younger population in the Arab world may contribute to the less death cases of COVID-19 in comparison with the topmost affected countries.
\end{abstract}

Key words: Arab world, Coronavirus, COVID-19, SARS-CoV-2. 


\section{Introduction}

The coronavirus disease 2019 (COVID-19) is a highly transmittable viral infection. By March 01, 2021, it has infected 114,687,163 and caused 2,543,285 deaths around the globe [1]. COVID19 is caused by severe acute respiratory syndrome-coronavirus 2 (SARS-CoV-2) [2], a positivesense, single-stranded RNA virus belonging to the genus Betacoronavirus [3]. Betacoronavirus also includes severe acute respiratory syndrome coronavirus (SARS-CoV) and Middle East respiratory syndrome coronavirus (MERS-CoV), both of which have caused SARS and MERS in 2003 and 2012, respectively [4]. Although SARS-CoV-2 shares about 79\% of its genome sequencing with SARS-CoV, however, it is much more infectious [5].

The clinical hallmarks of COVID-19 include fever, dry cough, sore throat, headache, fatigue and breathlessness. In some cases, COVID-19 patients also showed that the disease could progress to pneumonia, hypoxemia, acute respiratory distress syndrome, septic shock, blood clotting dysfunction, multiple organ failure and finally death [6]. Coughing and sneezing are the main spread mode of SARS-CoV-2 between humans. Several studies reported that close contact with COVID-19 patients are at high risk of infection [7,8]. Although almost everyone is vulnerable to this virus, elderly people and those with hypertension, diabetes, respiratory system disease, cardiovascular disease and cancers are more susceptible to COVID-19 [9,10], however, the prevalence of COVID-19 in children is less $[11,12]$. Several studies reported that men are more prone to infection and death of COVID-19 than women $[13,14,15]$. 
The recent introduction of the COVID-19 vaccines such as Pfizer-BioNTech, Moderna, OxfordAstraZeneca, Johnson \& Johnson, Gamaleya, CanSino, and Sinopharm is hoping to reduce the incidence of cases and protect more people. However, the insufficient production and late arrivals of the COVID-19 vaccination as well as unwillingness for many people to be vaccinated are another concern in many countries. Those who are hesitant to receive COVID-19 vaccination are afraid about the vaccine safety [16,17]. For this reason, many countries worldwide have launched COVID-19 vaccination campaigns.

Arab world contains 22 countries distributed as 12 in Asia and 10 in Africa. The Arab league was formed to unite the Arab countries politically and to represent the interests of the people. However, gender, race, socio-economic classes, layout and health care systems differ from one Arab country to another. Previously, we published the COVID-19 data in all Arab countries for a duration of five months and concluded that most Arab countries took some serious early steps to minimize the outbreak of COVID-19 [18]. In this review, we aimed to assess further the prevalence of COVID-19 in the Arab world from February 2020 to February 2021 and to compare these findings with other most affected countries. 


\section{Methodology}

We used World Health Organization (WHO), Worldometer and Ministries of Health websites to search for COVID-19 data in Algeria, Bahrain, Comoros, Djibouti, Egypt, Iraq, Jordan, Kuwait, Lebanon, Libya, Mauritania, Morocco, Oman, Palestine, Qatar, Saudi Arabia (SA), Somalia, Sudan, Syria, Tunisia, United Arab Emirates (UAE), and Yemen. The period was from February 2020 to February 2021. Inclusion criteria include official information in clinically diagnosed COVID-19 in English or Arabic. Exclusion criteria include unofficial information regarding COVID-19 in all Arab countries, language restrictions to English or Arabic only and unspecified date and location of the information or suspicion of duplicate information. The following information was collected from each Arab country: total population, median age, date and number of the first announced cases, number of monthly confirmed, death and cured cases, preventive methods, and total testing methods used. The data was analyzed using the Statistical Package for the Social Sciences (SPSS) software version 23 (SPSS Inc., Chicago, IL, USA). Results are presented as numbers, percentages and means. 


\section{Results}

The total Arab population who live in Arab countries is 441,622,903. The first Arab country to officially report the presence of COVID-19 was UAE with five cases on January 29, 2020. Egypt was the second Arab country and the first Arab-African country to declare the presence of COVID-19 on February 14, 2020. Comoros was the last of the Arab countries to declare the presence of COVID-19 on April 30, 2020. Palestine reported the highest number of the first announcement of COVID-19 with seven cases. The highest median age was in UAE with 38.4 whereas the lowest one was in Sudan with 18.3. Egypt recorded the highest population with 103,604,518 whereas Comoros showed only 881,774 people. All Arab countries utilized realtime polymerase chain reaction (RT-PCR) as the testing method for SARS-CoV-2. UAE performed the highest number of RT-PCR with 30,665,851 tests, followed by SA and Iraq with 13,633,077 and 6,846,243 tests, respectively. Yemen performed the lowest number of RT-PCR with only 17,404 tests (Table 1$)$.

As of March 01, 2021, the total number of COVID-19 cases in all Arab countries was 4,259,756. In terms of total confirmed cases with COVID-19, Iraq, Morocco, Jordan, UAE and SA recorded the highest reported cases with, 695,489, 483,766, 391,090, 390,453 and 377,383 respectively. Based on the evaluation of 12 months from February 2020 to February 2021, the trend showed that the month of November had the highest number of confirmed COVID-19 cases in all Arab countries with 631,692 cases. In the same month, Jordan, Morocco, Iraq, Lebanon, and Tunisia, scored the highest confirmed cases (Table 2). 
The total number of deaths in all Arab countries were 72,950 cases. Total number of deaths in the studied period was dominant in Iraq, followed by Egypt, Morocco, Tunisia and SA with 13,406, 10736, 8637, 8022 and 6494, respectively. The trend demonstrated that November had the highest number of deaths in all Arab countries with 10,797 cases. In the same month, Morocco, Tunisia, Jordan and Iraq had the highest death cases (Table 3).

The total number of cured cases in all Arab countries was 3,744,127. Iraq, Morocco, UAE, SA, and Jordan showed the highest number of cured cases with $635,931,469,345,381,221,367,033$, and 348,599, respectively. The trend showed that November had the highest number of cured cases in all Arab countries. In the same month, Jordan, Morocco, Iraq, Tunisia, and Lebanon scored the highest cured cases (Table 4).

The epidemiological data presented in Table 5 analyses the Arab world in comparison to the topmost 15 affected countries with COVID-19. This revealed that Arab countries are ranked fourth after the USA, India, and Brazil based on confirmed cases of COVID-19. The data on total deaths per million showed that Arab countries ranked second last before India, with only 165 cases. In terms of the total number of molecular tests for SARS-CoV-2, Arab countries are ranked fifth after USA, India, Russia, and UK with 76,568,739 tests. Arab countries showed the youngest median age with only 26.25 whereas Germany showed the oldest median age with 47.8. Other parameters, which include confirmed cases, cases per million, cured cases, tests per million and population, are also compared in Table 5. 


\section{Discussion}

Despite that many Arab countries took early serious measures to control the infection of COVID19 such as suspension of flights and many events, closure of universities and schools, lockdown of major cities, social distancing, quarantine and wearing of facial masks, COVID-19 is still rapidly on the rise. However, due to the economic crisis, many Arab countries as with other global countries lifted the restrictions prior to the satisfactorily reduction of confirmed and death cases of COVID-19. Such an approach could lead to higher numbers of mortality and morbidity.

In the current study, we have been following the COVID-19 cases in all Arab countries since it started. The number of confirmed cases has continued to increase gradually in most of the studied countries and peaked in July 2020. The possible reason for that peak was that many countries had reopened the shopping malls, private businesses and offices at full capacity [19]. In August 2020, the trend of confirmed cases showed a decline in most of the Arab countries except in Syria, Algeria, Libya, Oman, Tunisia, Morocco, Iraq and Lebanon. This is because many countries reimposed extra restrictions and preventative measures to contain the peak such as banning international flights, suspending Umrah and cancelling Hajj for the first time in SA since 1932 [20-22].

Noticeably, Iraq has recorded the highest number of confirmed, death and cured cases. Despite of air travel ban in Iraq, COVID-19 confirmed cases escalated because the returning Iraqi citizens were exempted [23]. Iraq showed a dramatic increase in the confirmed cases starting from July 2020. The possible explanations for that are lack of medical support and the relaxation 
of both curfews and movement restrictions by the authorities [24]. In addition, the partial reopen of the border between Iraq and Iran for foodstuff trading has contributed to the increase of the confirmed cases [25]. In December 2020, Europe reported a new variant of COVID-19 [25], which could likely be one of the reasons for the increasing prevalence of confirmed cases in many countries observed in January and February 2021.

Since the beginning of the COVID-19 crisis, the total death cases in the Arab countries was highest in November, followed by a fluctuation between a slight decline and elevation. This might be attributed to several factors such as: (i) the improvement of medical management and the coordinated efforts of the health system, (ii) medical caregivers became more familiar in dealing with the crisis and in alleviating patients' suffering, (iii) the community awareness and education of COVID-19 prompted immediate efforts in seeking of medical treatment to decrease disease severity, (iv) the use of drugs such as Remdesivir, Tocilizumab, and Baricitinib increased the quality of medical care [26-28], and (v) increased number of tests and testing methods contributed to the reduction of the overall death rate as high numbers of tests enabled healthcare providers to quickly detect and assess more cases with mild symptoms or even asymptomatic cases. Apart from the medical care management system, governmental restriction strategies such as closure of schools and businesses, bans on gatherings, quarantine for travelers, travel restrictions, maintaining physical distance and including orders to stay at home limited viral transmission and led to a drop in positive cases and, thus, a decrease in the deaths [29].

Although COVID-19 disease continues to be a big threat to the world, the numbers of cured cases are considered extremely high. Usually, healthy individuals assumed by their strong 
immunity can tolerate the flu-like symptoms of this disease. Nevertheless, very few rare cases of healthy young individuals have died from this pandemic without any clear evidence. Several factors might affect how the human body's immune defense system reacts to the virus. At the individual level, the genetic makeup of the human body can play a key role in immune responses. Lifestyle including healthy food and exercise play a major role in strengthening the immunity. This speculation can be true in countries like Iraq, which showed 635,931 cured cases as the top amongst the Arab countries (Table 4). Due to the unstable political conditions such as Iraq, people are forced to engage in utilizing their natural resources to manufacture their own local food and to work even harder to bring about positive changes. Another example is Morocco and Jordan that scored the highest cured cases in which these countries share similar climate and lifestyle that might influence the outcome of the disease.

Both the wealth of the country and the efficient health system have great influence on COVID19 cured cases such as UAE and SA that showed 381,221, and 367,033, respectively which are among the top countries. Overall, the trend in the cured cases showed some fluctuations which might be due to the above-mentioned factors that are either specific to some countries and not the others.

We have previously conducted a study to compare between the Arab world and the topmost 15 affected countries with COVID-19. As of May 31, 2020, the COVID-19 total confirmed cases for the Arab world showed 290,428 cases ranking it fourth amongst the top 15 countries [18]. Within a duration of 9 months, the total confirmed cases increased to 76,568,739 cases by March 01, 2021 representing an alarming situation despite maintaining the same rank (Table 5). The 
other 15 countries also showed an increasing trend of confirmed cases, however, Colombia, Argentina and Poland superseded Peru, Chile and Canada climbing up to the top 15 affected countries. While the Arab world may be ranked fourth in terms of the total confirmed cases, its rank is second last before India in terms of cases per million population (9321) and deaths per million population (165). These are very encouraging figures and indicate that the Arab world after India has fewer cases as a percentage of its population as compared to the rest of the top affected countries as shown in Table 5.

The other important parameter is the adequacy of testing. Increasing testing capacity is one of the measures implemented to control the spread of COVID-19. The top 15 countries including the Arab world showed increasing testing capacity in the number of tests per million conducted from May 31, 2020 to March 01, 2021. Italy, Spain, and Germany were reported to scale up testing and flatten the curve faster than other countries [30]. Despite these figures, there is still criticism whether all the cases are being detected.

Several studies have considered that older age plays a vital role in influencing the severity of COVID-19 disease and negative clinical outcomes than the younger population [31-33]. The Arab world followed by India has the youngest median age and this could partly explain the lower deaths per million population compared to the 13 top affected countries. Surprisingly, Mexico also had a significant young median age of 29.3 compared to Germany (median age $=$ 47.8) but recorded 1430 deaths per million whereas Germany had a much lower death per million of 842 . 
Our study is not an exemption of limitations. First, some potential risk factors, such as signs and symptoms, gender, age, death causes, medications, duration of hospital admission and other confounders (hypertension, diabetes, respiratory system disease and cardiovascular disease), that can be associated with the confirmed, death and cured cases of COVID-19 were not available. Second, many patients who were asymptomatic or had mild symptoms and who were treated at home might not be included in these data. Thirdly, many non-Arab nationalities work in Arab countries and most of the published data did not distinguish Arabs from non-Arabs. Finally, while the data of tests per million are instructive of demonstrating increasing testing capacity, it is not known whether some countries record the number of people tested or record the total number of tests carried out as some people may require more numbers of tests to obtain accurate results.

In conclusion, the number of confirmed and death cases among all Arab countries trigger vital worries about morbidity and mortality of COVID-19, respectively. However, younger population in the Arab world may contribute to the less death cases of COVID-19 in comparison with the topmost affected countries.

\section{Conflicts of interest}

The authors declare no conflict of interest. 


\section{References}

1. World Population Clock - Worldometer (2020). Available: https://www.worldometers.info/world-population. Accessed 01 March 2021.

2. Paraskevis D, Kostaki EG, Magiorkinis G, Panayiotakopoulos G, Sourvinos G, Tsiodras S. Full-genome evolutionary analysis of the novel corona virus (2019-nCoV) rejects the hypothesis of emergence as a result of a recent recombination event. Infect Genet Evol 2020;79:104212. https://doi.org/10.1016/j.meegid.2020.104212

3. Chan JF, Kok KH, Zhu Z, Chu H, To KK, et al. Genomic characterization of the 2019 novel human-pathogenic coronavirus isolated from a patient with atypical pneumonia after visiting Wuhan. Emerg Microbes Infect 2020;9:221-36. https://doi.org/10.1080/22221751.2020.1719902

4. Coronaviridae Study Group of the International Committee on Taxonomy of Viruses. The species severe acute respiratory syndrome-related coronavirus: classifying 2019-nCoV and naming it SARS-CoV-2. Nat Microbiol 2020;5(4):536-44. https://doi.org/10.1038/s41564-020-0695-Z

5. Zhu N, Zhang D, Wang W, Li X, Yang B, Song J, et al. A Novel Coronavirus from Patients with Pneumonia in China, 2019. N Engl J Med 2020;382:727-33. https://doi.org/10.1056/NEJMoa2001017

6. Guan W, Ni Z, Hu Y, Liang W, Ou C, He J. et al. Clinical characteristics of 2019 novel coronavirus infection in China. N Engl J Med 2020;382:1708-20.

https://doi.org/10.1101/2020.02.06.20020974

7. de Wit E, van Doremalen N, Falzarano D, Munster VJ. SARS and MERS: recent insights into emerging coronaviruses. Nat Rev Microbiol 2016;14:523-34. https://doi.org/10.1038/nrmicro.2016.81

8. Sohrabi C, Alsafi Z, O’Neill N, Khan M, Kerwan A, Al-Jabir A, et al. World Health Organization declares global emergency: A review of the 2019 novel coronavirus (COVID-19). Emerg Microbes Infect 2020;76:71-6. https://doi.org/10.1016/j.ijsu.2020.02.034 
9. Zhang J, Dong X, Cao Y, Yuan Y, Yang Y, Yan Y, et al. Clinical characteristics of 140 patients infected with SARS-CoV-2 in Wuhan, China. Allergy 2020;75:1730-41. https://doi.org/10.1111/all.14238

10. Yang J, Zheng Y, Gou X, Pu K, Chen Z, Guo Q, et al. Prevalence of comorbidities and its effects in patients infected with SARS-CoV-2: a systematic review and meta-analysis. Int J Infect Dis 2020;94:91-5. https://doi.org/10.1016/j.ijid.2020.03.017

11. Lu X, Zhang L, Du H, Zhang J, Li Y, Qu J, et al. SARS-CoV-2 Infection in Children. N Engl J Med 2020;382:1663-5. https://www.nejm.org/doi/full/10.1056/NEJMc2005073

12. Qiu H, Wu J, Hong L, Luo Y, Song Q, Chen D. Clinical and epidemiological features of 36 children with coronavirus disease 2019 (COVID-19) in Zhejiang, China: an observational cohort study. Lancet Infect Dis 2020;20:689-96. https://doi.org/10.1016/s1473-3099(20)30198-5

13. Wenham C, Smith J, Morgan R. COVID-19: the gendered impacts of the outbreak. Lancet. 2020;395:846-848. https://doi.org/10.1016/s0140-6736(20)30526-2

14. Jin JM, Bai P, He W, Wu F, Liu X, Han D, et al. Gender Differences in Patients With COVID-19: Focus on Severity and Mortality. Front Public Health 2020;8:152. https://doi.org/10.3389/fpubh.2020.00152

15. Hall KS, Samari G, Garbers S, Casey SE, Dixon Diallo D, Orcutt M, et al. Centring sexual and reproductive health and justice in the global COVID-19 response. Lancet. 2020. https://doi.org/10.1016/s0140-6736(20)30801-1

16. C Lin, P Tu, LM Beitsch. Confidence and receptivity for COVID-19 vaccines: a rapid systematic review. Vaccines (Basel), 2020;9:e16. https://doi.org/10.3390/vaccines9010016

17. Lazarus JV, Ratzan SC, Palayew A, Gostin LO, Larson HJ, Rabin K. et al. A global survey of potential acceptance of a COVID-19 vaccine. Nat Med 2021;27:225-8. 
https://doi.org/10.1038/s41591-020-1124-9

18. Alwahaibi N, Al-Maskari M, Al-Dhahli B, Al-Issaei H, Al-Bahlani S. A review of the prevalence of COVID-19 in the Arab world. J Infect Dev Ctries 2020;14:1238-45. https://doi.org/10.3855/jidc.13270

19. Alyami M, Naser A, Orabi M, Alwafi H, Alyami H. Epidemiology of COVID-19 in the Kingdom of Saudi Arabia: An Ecological Study. Front Public Health 2020;8:506. https://doi.org/10.3389/fpubh.2020.00506

20. Adly H, AlJahali I, Garout M, Khafagy A, Saati A, Saleh S. Correlation of COVID-19 pandemic with healthcare system response and prevention measures in Saudi Arabia. Int J Environ Res Public Health 2020;17:1-13. https://doi.org/10.3390/ijerph17186666

21. Alandijany T, Faizo A, Azhar E. Coronavirus disease of 2019 (COVID-19) in the Gulf Cooperation Council GCC countries: Current status and management practices. J Infect Public Health 2020; 13:839-842. https://doi.org/10.1016/j.jiph.2020.05.020

22. Saudi Arabia extends covid measures by another 20 days. News Article by Argus published on $14 . \quad$ Feb.2021. Available from: https://www.argusmedia.com/en/news/2186868-saudi-arabia-extends-covid-measuresby-another-20-days

23. Al-Malkey, M., \& Al-Sammak, M. Incidence of COVID-19 in Iraq-Implications for travelers. Travel Medicine and Infection Disease 2020;38:1-3. https://dx.doi.org/10.1016\%2Fj.tmaid.2020.101739

24. Sarhan A, Flaih M, Hussein T, Hussein K. Novel coronavirus (COVID-19) outbreak in Iraq. The first wave and future scenario. MedRxiv preprint doi: https://doi.org/10.1101/2020.06.23.20138370 posted on 26.June.2020.

25. Latest on the region's Covid-19 recovery. Middle East Business Intelligence. Available from: https://www.meed.com/latest-news-on-the-pandemics-economic-impact. 
26. Paladugu S, Donato A. Remdesivir improved time to recovery in adults hospitalized with COVID-19 and lower respiratory tract involvement. Ann Intern Med 2020;173(2):JC4. https://doi.org/10.7326/acpj202007210-005

27. Malgie J, Schoones J, Pijls B. Decreased mortality in coronavirus disease 2019 patients treated with tocilizumab: a rapid systematic review and meta-analysis of observational studies. Clin Infect Dis 2020;2(2):1-8. https://doi.org/10.1093/cid/ciaa1445

28. Hasan M, Rabbani R, Anam A, Huq S. Additional baricitinib loading dose improves clinical outcome in COVID-19. Open Medicine, 2020;16(1):041-6. https://doi.org/10.1515/med-2021-0010

29. Horwitz L, Jones S, Cerfolio R, Francois F, Greco J, Rudy B, et al. Trends in COVID-19 risk-adjusted mortality rates. J Hosp Med 2020;16(2):90-2. https://doi.org/10.12788/jhm.3552

30. Verity R, Okell LC, Dorigatti I, Winskill P, Whittaker C, Imai N, et al. Estimates of the severity of coronavirus disease 2019: a model-based analysis. Lancet Infect Dis 2020;20:669-77. https://doi.org/10.1016/s1473-3099(20)30243-7

31. Esteve A, Permanyer I, Boertien D, Vaupel JW. National age and coresidence patterns shape COVID-19 vulnerability. Proc Natl Acad Sci U S A 2020;117:16118-20. https://doi.org/10.1073/pnas.2008764117

32. Oksanen A, Kaakinen M, Latikka R, Savolainen I, Savela N, Koivula A. Regulation and Trust: 3-Month Follow-up Study on COVID-19 Mortality in 25 European Countries. JMIR Public Health Surveill 2020;6:e19218. https://doi.org/10.2196/19218.

33. Wu J, Leung TK, Bushman M, Kishore N, Niehus R, de Salazar PM, et al. Estimating clinical severity of COVID-19 from the transmission dynamics in Wuhan, China. Nat Med 2020;26:506-10. https://doi.org/10.1038/s41591-020-0822-7 